\section{Zahlen des Monats}

\section{Bessere Versorgung}

Die zahnmedizinische Versorgung für Pflegebedürftige und Menschen mit Behinderung nimmt weiter zu. Laut aktueller Statistik der Kassenzahnärztlichen Bundesvereinigung stieg die Zahl der Kooperationsverträge zwischen Zahnärzten und stationären Pflegeeinrichtungen bis Ende Dezember 2016 im Vergleich zum Vorjahr um 610 Verträge auf 3.218. Die Abdeckung entspricht damit bei derzeit 13.596 Pflegeheimen bundesweit etwa 24 Prozent. Daneben stieg die Gesamtzahl der zahnärztlichen Besuche von Pflegebedürftigen in Heimen und zu Hause im Jahr 2016 auf etwa 902.000, das entspricht einem Plus von 5,6 Prozent im Vergleich zum Vorjahr.

\section{Höhere Lebenserwartung}

Was lange für unmöglich gehalten wurde, hat ein Londoner Forscherteam durch die Untersuchung von Geburtsund Sterbedaten aus 35 Ländern belegt: Die durchschnittliche Lebenserwartung könnte bald bei 90 Jahren liegen. Demnach steigt die Lebenserwartung gerade in Industrienationen stetig. So könnten ab dem Jahr 2030 viele Menschen in den untersuchten Ländern mit großer Wahrscheinlichkeit ihr 90. Wiegenfest feiern. Dabei steigt für Männer die Lebenserwartung mit einer deutlich höheren Wahrscheinlichkeit (mindestens 85 Prozent) als für Frauen (65 Prozent). Damit dürfte sich die Kluft zwischen Männern und Frauen bis 2030 stark annähern.

\section{Hehre Werte}

Familie und Partnerschaft gehen akademischen Heilberuflern über alles. Das hat eine Studie der Deutschen Apotheker- und Ärztebank unter 500 Ärzten, Apothekern, Zahnärzten sowie Medizin- und Pharmaziestudenten herausgefunden. 91 Prozent der Befragten gaben an, das Familienleben sei für sie am wichtigsten, gefolgt von der finanziellen Sicherheit (85 Prozent) und der Möglichkeit, Menschen zu helfen (83 Prozent). Nur 45 Prozent der Befragten war das berufliche Vorankommen am wichtigsten.

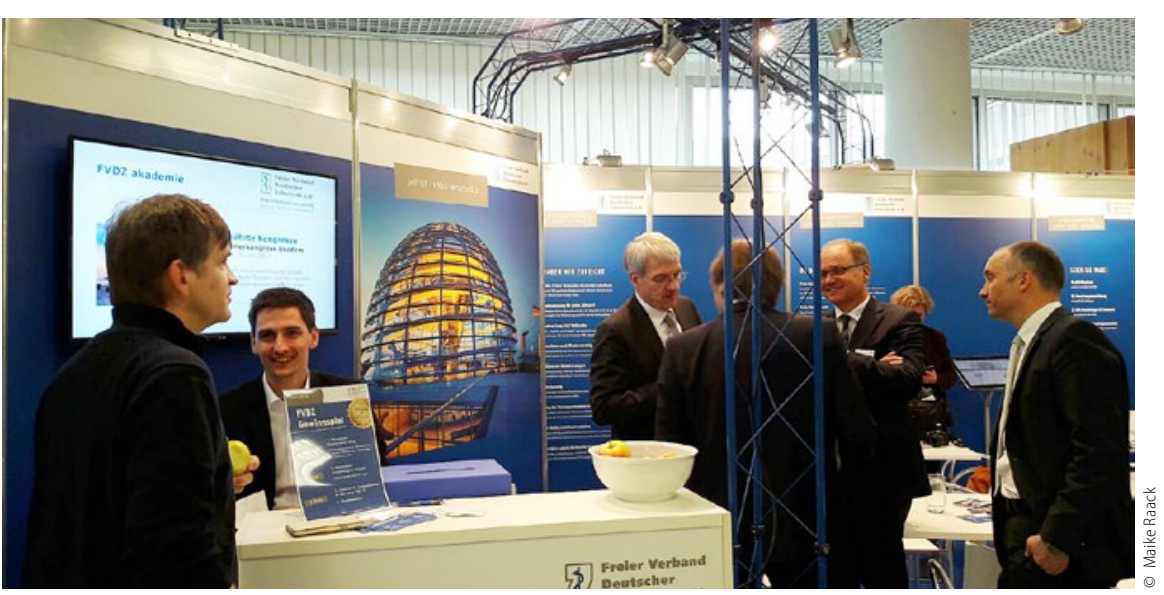

Der Freie Verband auf der Internationalen Dental-Schau

\section{Am Puls der Zeit}

Größer, innovativer, interessanter: Die 37. Internationale Dental-Schau (IDS) in Köln hat sich im März wieder selbst übertroffen. Nicht nur die Industrie ist beim weltgrößten Branchentreff mit neuen Ständen, neuen Produkten und jeder Menge publikumswirksamer Messe-Highlights aufgewartet. Auch der Freie Verband Deutscher Zahnärzte hat sich inmitten der 2.300 Aussteller aus 60 Ländern modern und ansprechend präsentiert.

Am FVDZ-Stand mit neuem Look konnten sich Zahnmedizinstudenten und Existenzgründer genauso wie erfahrene Zahnärzte und Praxismitarbeiter darüber informieren, wofür der Freie Verband steht und welche Vorteile er bietet. Erstmals standen die vier Top-Themen Freiberuflichkeit, Kongresse und Seminare, Praxisführung und Praxisgründung sowie Praxisabgabe und Praxissuche im Fokus. Wer hierzu Infos suchte, bekam diese entweder interaktiv oder ganz klassisch im Gespräch - zum Beispiel mit dem FVDZ-Bundesvorsitzenden Harald Schrader (Foto: Dritter von links).

Was auf der IDS noch so passierte, welche Trends der Zahnmedizin und Zahntechnik auf dem Vormarsch sind und wer sich über die Preise des FVDZ-Gewinnspiels freuen kann, ist in der Mai-Ausgabe zu lesen.

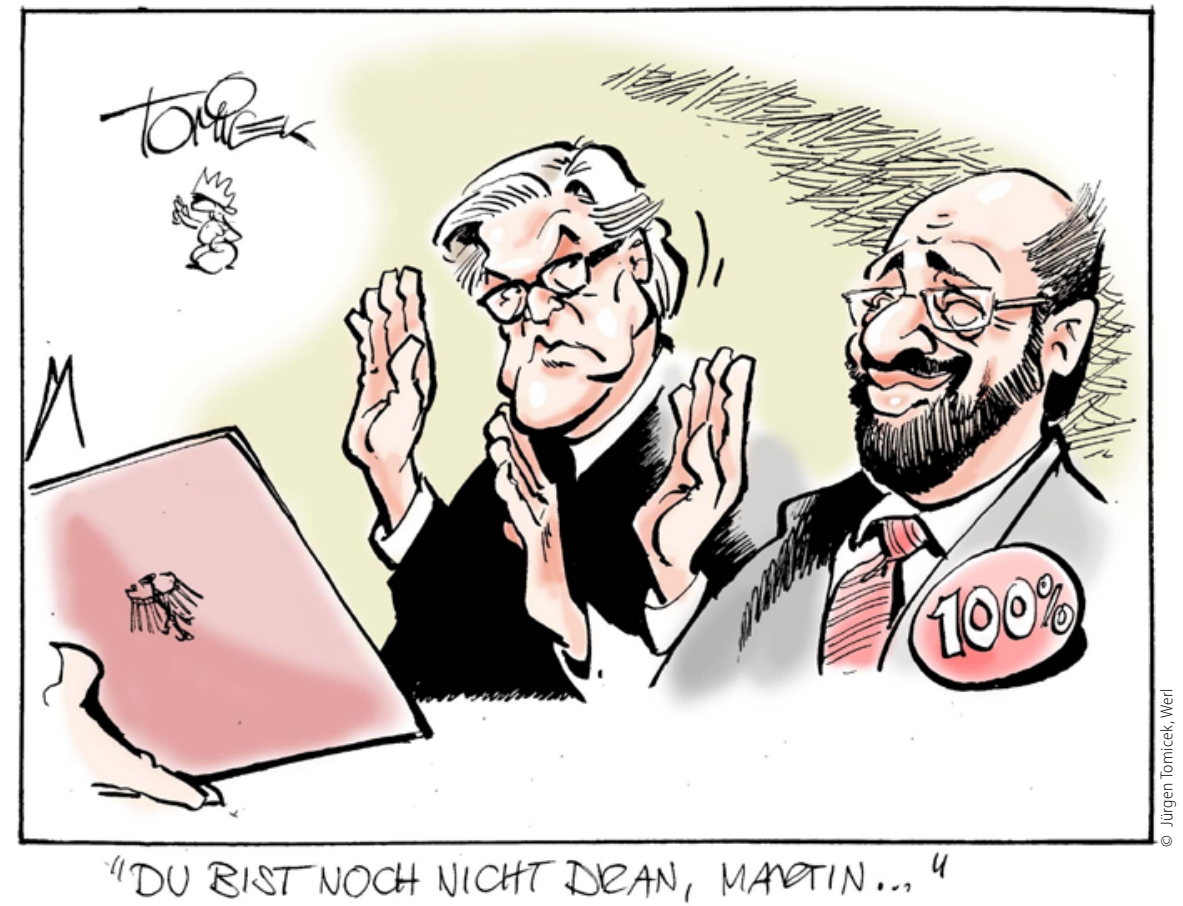

